\title{
A positive role for C-Abl in Atm and Atr activation in DNA damage response
}

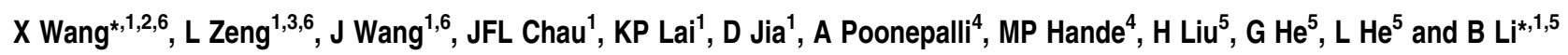

DNA damage triggers Atm- and/or Atr-dependent signaling pathways to control cell cycle progression, apoptosis, and DNA repair. However, how Atm and Atr are activated is not fully understood. One of the downstream targets of Atm is non-receptor tyrosine kinase c-Abl, which is phosphorylated and activated by Atm. The current view is that c-Abl relays pro-apoptotic signals from Atm to p73 and p53. Here we show that c-Abl deficiency resulted in a broad spectrum of defects in cell response to genotoxic stress, including activation of Chk1 and Chk2, activation of p53, nuclear foci formation, apoptosis, and DNA repair, suggesting that c-Abl might also act upstream of the DNA damage-activated signaling cascades in addition to its role in p73 and p53 regulation. Indeed, we found that C-Abl is required for proper activation of both Atm and Atr. C-Abl is bound to the chromatin and shows enhanced interaction with Atm and Atr in response to DNA damage. C-Abl can phosphorylate Atr on Y291 and Y310 and this phosphorylation appears to have a positive role in Atr activation under genotoxic stress. These findings suggest that Atm-mediated c-Abl activation in cell response to double-stranded DNA breaks might facilitate the activation of both Atm and Atr to regulate their downstream cellular events.

Cell Death and Differentiation (2011) 18, 5-15; doi:10.1038/cdd.2010.106; published online 27 August 2010

DNA damage can be caused by exogenous or endogenous factors such as ionizing radiation (IR), chemotherapeutic drugs, and stalled replication forks. ${ }^{1}$ It is believed that various DNA lesions are eventually converted to double-stranded breaks (DSBs) and/or single-stranded DNA (ssDNA or SSBs), where sensors, mediators, transducers, and effectors assemble to form nuclear foci, which function as centers of signal propagation. At the core of the signaling network are PI-3 kinase-like kinases (PIKKs), including Atm, Atr and DNA-PKcs. ${ }^{2}$ Atm is mainly activated by DSBs, whereas Atr responds to various DNA lesions. ${ }^{3}$ Atm and Atr are recruited to the nuclear foci by the MRN (Mre11-Rad50-NBS) complex and ATRIP, respectively, ${ }^{4,5}$ where they phosphorylate proteins such as p53, Chk1, Chk2, and $\mathrm{H} 2 \mathrm{AX}$, to activate cell cycle checkpoints and/or induce apoptosis. ${ }^{6}$ Phosphorylation of Chk1 and Chk2 by Atr and Atm is facilitated by a group of nuclear foci proteins called mediators, for example, Brca1, TopBP1, and 53BP1. Furthermore, the nuclear foci also function as repair centers. ${ }^{7}$ DSB repair is believed to involve an Atm to Atr switch. ${ }^{8,9}$ Atm is first recruited to DSBs and SSDNA is later generated by resection of the DNA ends, where Atr can be assembled and activated. Thus, there exists a complex functional interaction between these two PIKKs. ${ }^{10}$ Although several proteins have been reported to activate Atm or Atr, ${ }^{11,12}$ the initial activation of Atm/Atr and the regulation of their activities in the process of DNA repair are poorly understood. ${ }^{13,14}$
The c-Abl proto-oncogene encodes a non-receptor tyrosine kinase that is essential for perinatal survival in mice. ${ }^{15} \mathrm{c}$-Abl has been implicated in DNA damage response. It is activated by IR and radiomimetic reagents in an Atm-dependent manner. ${ }^{16,17}$ It is generally believed that the role for c-Abl in DNA damage response is to relay pro-apoptotic signals from Atm to $\mathrm{p} 53$ and $\mathrm{p} 73,{ }^{18}$ whereas it remains controversial whether c-Abl has a function in cell cycle control and in DNA repair. ${ }^{19}$ Moreover, $c-A b l$ has been reported to interact with a number of mediator or repair proteins, including TopBP1, Brca1, and Rad51. ${ }^{20,21}$ However, the significance of these interactions is not well understood. Therefore, the roles for $c-A b l$ in DNA damage response can be complex and require further investigation.

Here we used primary, non-immortalized c-Abl-/- mouse embryonic fibroblasts (MEFs) to study the function of $c-A b l$ in DNA damage response, as cell immortalization and transformation considerably alter cell response to DNA damage. ${ }^{22}$ We found that c-Abl deficiency results in a range of defects in response to DSBs, which cannot be simply explained by defects in regulation of $p 53$ and $p 73$. Moreover, ssDNA also activates c-Abl, which has an important role in the ssDNAelicited Atr-p53/Chk1 pathway and apoptosis. By following p53 $\mathrm{S} 18$ phosphorylation, this study reveals that $\mathrm{c}-\mathrm{Abl}$ positively regulates the activation of Atm/Atr by interacting with Atm/Atr and phosphorylating Atr on Y291 and Y310.

\footnotetext{
${ }^{1}$ Institute of Molecular and Cell Biology, Agency for Science, Technology, and Research, Singapore; ${ }^{2}$ Department of Biochemistry, Yong Loo Lin School of Medicine, Cancer Science Institute of Singapore, Singapore; ${ }^{3}$ Neural Stem Cells Research Laboratory, National Neuroscience Institute, Singapore; ${ }^{4}$ Department of Physiology, National University of Singapore, Singapore and ${ }^{5}$ Bio-X Center, Key Laboratory for the Genetics of Developmental and Neuropsychiatric Disorders, Ministry of Education, Shanghai Jiao Tong University, Shanghai, China

${ }^{*}$ Corresponding authors: B Li, Institute of Molecular and Cell Biology, 61, Bioplois Drive, Singapore 138673, Singapore.

Tel: 65-6586-9679; Fax: 65-67791117; E-mail: libj@imcb.a-star.edu.sg or X Wang, Department of Biochemistry, Yong Loo Lin School of Medicine; Cancer Science Institute of Singapore (CSI), National University of Singapore, 28 Medical Drive, Singapore 117456. Tel: 65-65165995; Fax: 65-68739664;

E-mail: xueying_wang@nuhs.edu.sg

${ }^{6}$ These authors contributed equally to this work.

Keywords: c-Abl; Atm; Atr; phosphorylation; DNA repair

Abbreviations: Chk1/2, checkpoint kinase 1 and 2; Dox, doxorubicin; DSBs, double-strand breaks; $\gamma \mathrm{H} 2 \mathrm{AX}$, phosphorylated form of H2AX

Received 03.2.10; revised 08.7.10; accepted 20.7.10; Edited by V De Laurenzi; published online 27.8.10
} 
These findings advance our understanding of the activation of Atm/Atr and the function of $c-A b l$ in DNA damage response.

\section{Results}

c-Abl is required for Atm/Atr-mediated phosphorylation of p53, Chk1, and Chk2. To re-examine the role for c-Abl in DNA damage response, we challenged the primary MEFs with IR or doxorubicin/adriamycin (Dox), a chemotherapeutic agent and a topoisomerase II inhibitor that generates DSBs and SSBs. ${ }^{23}$ IR activates $\mathrm{c}-\mathrm{Abl}$ and $\mathrm{p} 53$ in a rapid but transient way, ${ }^{6,16,17}$ whereas Dox-induced p53 upregulation and $\mathrm{c}-\mathrm{Abl}$ activation took much longer time in MEFs (Figure $1 \mathrm{a}$ and b). Dox also induced p53 phosphorylation on S18 (human p53 S15), which is carried out by Atm, Atr or DNAPKcs, but barely on S9 or S23; c-Abl deficiency led to a marked decrease in $\mathbf{S 1 8}$ phosphorylation, but to a smaller effect on p53 upregulation (Figure 1a and data not shown). Similar results were obtained in primary MEFs with c-Abl being knocked down by siRNA (Supplementary Figure S1a). c-Abl-/- MEFs also showed a decrease in the induction of p53 target genes p21, 14-3-3 $\sigma$, and Gadd45 (Supplementary Figure $\mathrm{S} 1 \mathrm{~b}$ and $\mathrm{c}$ ). Similarly, IR-induced p53 upregulation, S18 phosphorylation, and induction of p53target genes were all defective in c-Abl-/- MEFs that were rescued by c-Abl reconstitution (Supplementary Figure $\mathrm{S} 2 \mathrm{a}-\mathrm{c}$ ). It is to be noted that IR altered the protein levels of p53 to a lesser extent than that of S18 phosphorylation, confirming that c-Abl deficiency compromises signal transduction from Atm/Atr/DNA-PKcs to p53 in response to DSBs.

In addition, Dox-induced activation of Chk1 and Chk2, which are phosphorylated by Atr and Atm, respectively, was markedly reduced in $\mathrm{c}-\mathrm{Abl}-/-$ or $\mathrm{c}-\mathrm{Abl}$ knockdown MEFs (Figure 1c and Supplementary Figure S1d), suggesting that c-Abl might regulate both Atm- and Atr-mediated pathways. To confirm the role for c-Abl in ssDNA-induced cell response, which is not well understood, we treated $\mathrm{c}-\mathrm{Abl}-\mathrm{I}-$ and control MEFs with hydroxyurea (HU) or aphidicolin (APH), DNA synthesis blockers that mainly activate Atr. Again, c-Abl-/MEFs showed a compromised p53 phosphorylation (Figure 1d). Inhibition of c-Abl with STI571 or c-Abl knockdown also diminished $\mathrm{HU}$-induced p53 phosphorylation (Supplementary Figure $\mathrm{S} 3 \mathrm{a}$ and $\mathrm{b}$ ). We also found that c-Abl could be activated by HU treatment as indicated by the phosphorylation of GST-Crk1 in an in vitro kinase assay (Figure 1e). Taken together, these results indicate that c-Abl is involved in ssDNA-triggered Atr pathway in addition to DSBtriggered Atm pathway, and c-Abl might have a more profound effect on p53 S18 phosphorylation than on p53 upregulation under genotoxic stress generated by IR, Dox, HU, or APH.

\section{c-Abl deficiency leads to defects in genotoxic stress-induced apoptosis, cell cycle progression, and DNA repair. To validate the role of $\mathrm{c}$-Abl in Atm/Atr- mediated activation of p53 and Chk1/2, we analyzed their downstream cellular events, including cell cycle arrest, apoptosis, and DNA repair. Previous studies have shown that c-Abl-/- MEFs are resistant to apoptosis induced by DSBs generated by IR and several radiomimetic drugs. ${ }^{19}$}

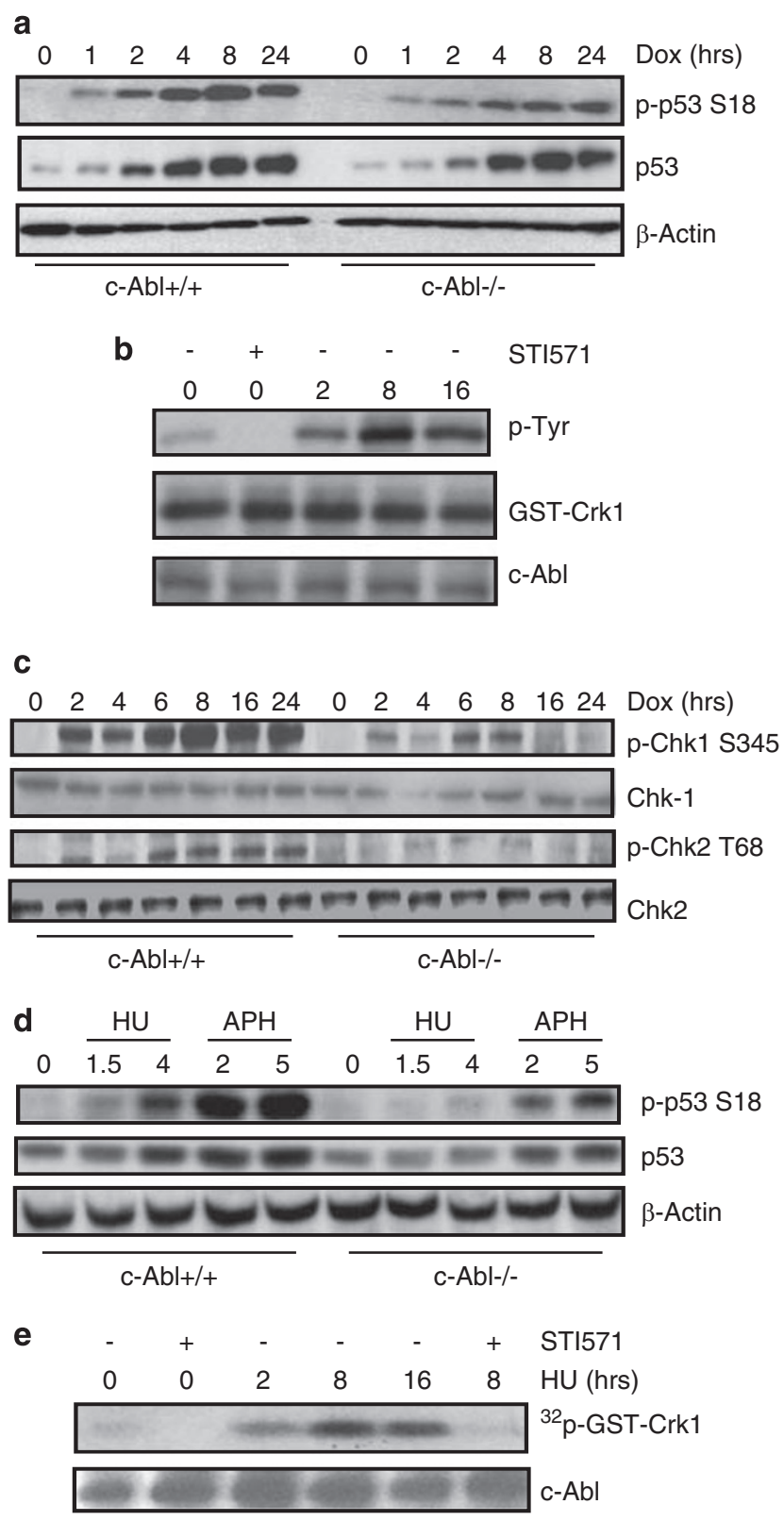

Figure $1 \mathrm{c}$-Abl-/- MEFs show defects in Atm/Atr-mediated p53 $\mathrm{S} 18$ phosphorylation and Chk1/2 phosphorylation. (a) C-Abl-l- MEFs showed decreased p53 phosphorylation at S18 in response to Dox. C-Abl-/- and control MEFs were challenged with $\mathrm{I} \mu \mathrm{M}$ of Dox for different periods of time and the levels of p53 and p-p53 S18 were analyzed with western blot. (b) Dox treatment could activate c-Abl. WT MEFs were stimulated with Dox for different periods of time in the presence or absence of STI571. Endogenous c-Abl was immunoprecipitated from these cells and was used for in vitro kinase assay using GST-Crk1 as a substrate. Tyr phosphorylation of Crk1 was detected by western blot using anti-p-Tyr antibodies. (c) C-Abl-I-MEFs showed decreased activation of Chk1 and Chk2 in response to Dox. The experiment was carried out as in (a). p-Chk1, p-Chk2, Chk1, and Chk2 were detected by western blot using specific antibodies. (d) c-Abl-IMEFs showed compromised p53 phosphorylation in response to $\mathrm{HU}(\mathrm{mM})$ and aphidicolin $(\mu \mathrm{g} / \mathrm{ml})$ for $8 \mathrm{~h} . \mathrm{p}$-p53 and p53 were detected by western blot using specific antibodies. (e) HU treatment could activate c-Abl. WT MEFs were stimulated with $\mathrm{HU}$ for different periods of time in the presence of absence of STI571. Endogenous C-Abl was immunoprecipitated from these cells and was used for in vitro kinase assay using GST-Crk1 as a substrate in the presence of ${ }^{32} \mathrm{P}$-labeled ATP 
This conclusion was confirmed with Dox treatment (data not shown). Moreover, we found that c-Abl-I- MEFs were similarly resistant to $\mathrm{HU}$-induced apoptosis. $\mathrm{HU}$ treatment at
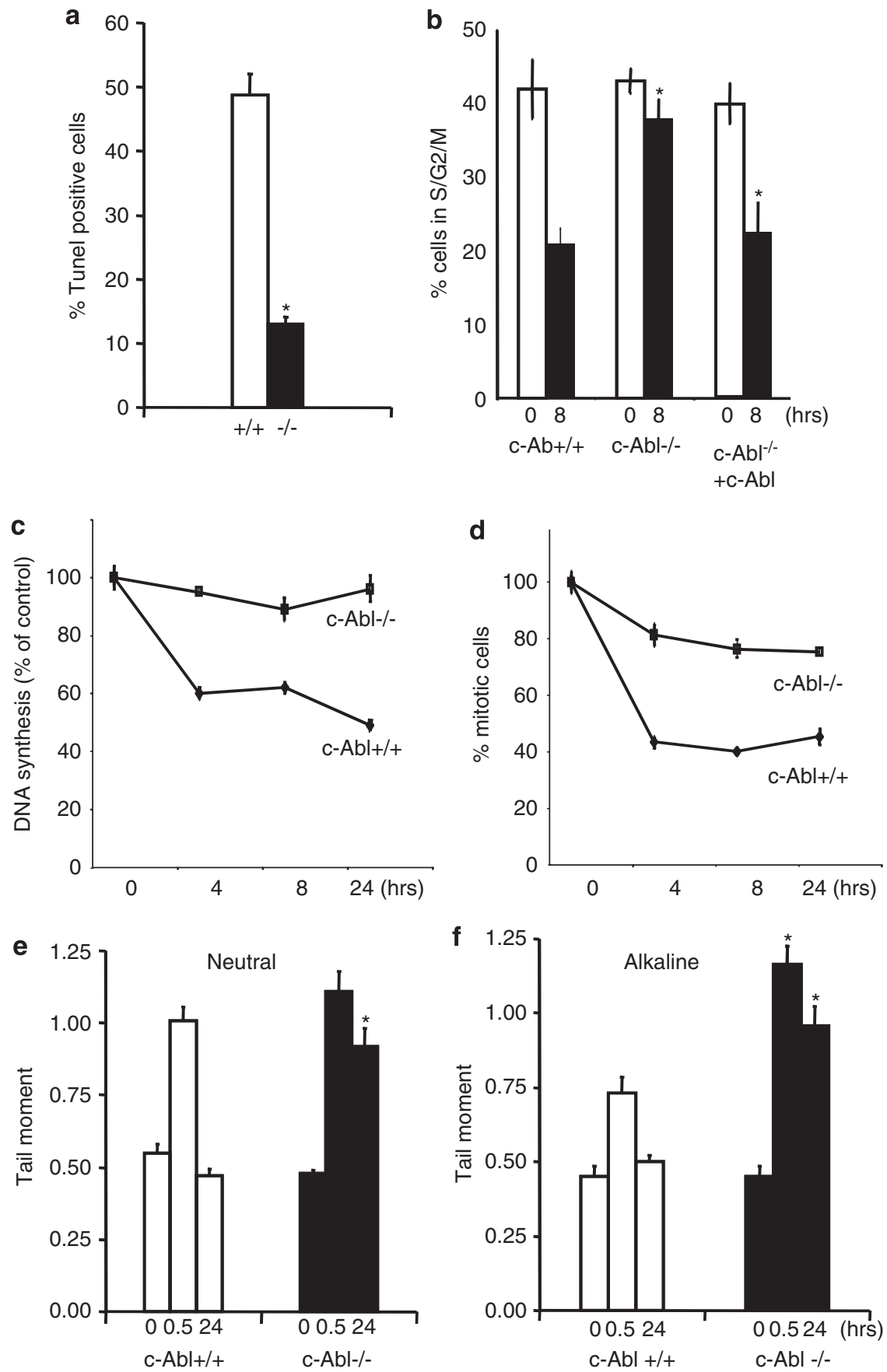

Figure $2 \mathrm{c}-\mathrm{Abl}-\mathrm{I}-\mathrm{MEFs}$ show defects in DNA damage-induced cell death, cell cycle progression, and DNA repair. (a) c-Abl-/-MEFs showed an increased resistance to cell death in response to HU. WT and mutant MEFs of the same litters were treated with $5 \mathrm{mM}$ of $\mathrm{HU}$ for $24 \mathrm{~h}$ and the cell viability was measured with TUNEL assays. (b) c-Abl-I-MEFs showed a defect in cell cycle control. c-Abl-I-, control, and reconstituted c-Abl-I-MEFs were challenged with $5 \mathrm{~Gy}$ of IR and cell cycle profiles were analyzed by FACS after PI staining. ${ }^{*} P<0.05$ when comparing control and $\mathrm{c}-\mathrm{Abl}-/-$ cells. (c) c-Abl-/- MEFs showed more RDS in response to IR. Replicative DNA synthesis was assessed at different time points after IR. The results were averages of at least triplicate samples. The resulting ratio of ${ }^{3} \mathrm{H}$ (c.p.m.) to ${ }^{14} \mathrm{C}$ (c.p.m.) was used as an indication of RDS. The ratio at time 0 was set at $100 \%$. (d) $c-A b l-/-$ MEFs showed more cells in the mitotic phase after IR, reflected by the increased percentage of cells positive for phospho-H3. Quantitation data were averaged over three experiments. The number of phospho-H3-positive cells at time 0 was set at $100 \%$. (e) c-Abl-/- MEFs showed normal levels of DSBs. c-AbI-/ - and control MEFs were challenged with IR, collected at 0.5 or $24 \mathrm{~h}$ after IR, and used for comet assay at neutral pH. ${ }^{*}$ indicates that $\mathrm{c}-\mathrm{Abl}-\mathrm{I}-\mathrm{MEFs}$ show a significant difference from WT MEFs at the same time point. (f) c-Abl-/- MEFs showed increased amounts of ssDNA. The experiment was carried out as in (e) except that comet assay was done at alkaline pH. ${ }^{*}$ indicates that c-Abl-I-MEFs show a significant difference from WT MEFs at the same time point 
We then studied cell cycle progression under genotoxic stress in c-Abl-/- MEFs, which has not been well studied. Flow cytometry analysis of $\mathrm{c}-\mathrm{Abl}-1-$ and control MEFs showed that about $42 \%$ of untreated wild-type or C-Abl-/MEFs was in S/G2/M phase. Eight hours after IR (5 Gy), most of the WT cells were arrested at G1 phase and only $20 \%$ of cells were in S/G2/M phase. However, c-Abl-/- MEF cultures had $37 \%$ of the cells in S/G2/M (Figure $2 b$ ). Reconstitution of $\mathrm{c}$-Abl with retrovirus rescued the defects observed in Abl-/MEFs (Figure $2 b$ ). These results suggest that c-Abl deficiency might promote the entry to the $S / G 2 / M$ phases or inhibit the exit from these phases. We then analyzed radio-resistant DNA synthesis (RDS) and found that c-Abl deficiency resulted in an increase in RDS in response to IR (Figure 2c). c-Abl-/MEFs also showed an increase in G2/M phase cells, as judged by elevated numbers of phospho-H3-positive cells (Figure $2 \mathrm{~d}$ ). These results confirm that $\mathrm{C}-\mathrm{Abl}$ has a critical role in DSB-induced cell cycle control.

We next examined a possible role for $c-A b l$ in DNA repair using the comet assay, a single-cell electrophoresis method used to quantify DSBs (neutral conditions) or ssDNA (alkaline conditions). c-Abl-/- and control MEFs were irradiated with $2.5 \mathrm{~Gy}$ of IR and the cells were collected after 0.5 or $24 \mathrm{~h}$. Unlike transformed cell lines, the number of ssDNA or DSBs was found to be low in primary cells. Nevertheless, it was observed that c-Abl-I-MEFs showed comparable numbers of DSBs at time 0 and $0.5 \mathrm{~h}$, but more DSBs $24 \mathrm{~h}$ after IR (Figure 2e), and c-Abl-/-MEFs showed more SSBs at both 0.5 and $24 \mathrm{~h}$ after IR (Figure $2 \mathrm{f}$ ). These results suggest that $\mathrm{c}$ Abl has a role in DNA repair, especially ssDNA. The results on apoptosis, cell cycle progression, and DNA repair indicate that $\mathrm{c}-\mathrm{Abl}$ has multiple functions in DNA damage response.

C-Abl deficiency differentially alters foci formation of TopBP1, $\gamma \mathrm{H} 2 \mathrm{AX}$, Atm/Atr, and other molecules. DNA repair efficacy is also reflected by the disappearance of DNA damage-induced foci. We analyzed several of the adaptor and repair proteins including TopBP1, a c-Abl interacting protein. Compared with IR, Dox generated more stable foci that can be easily quantitated. Dox treatment led to TopBP1 foci formation $1-2 \mathrm{~h}$ after treatment, with maximal foci formation being observed $16 \mathrm{~h}$ after treatment. After $24 \mathrm{~h}$ of treatment, cells started to lose the foci in WT MEFs. However, c-Abl-/- MEFs displayed an increase in the percentage of cells positive for the foci and in the number of foci per cell throughout the time course as compared with WT cells (Figure $3 a-c$ ), which could be restored upon $c-A b l$ reconstitution (Figure $3 a-c$ ). Moreover, c-Abl deficiency also resulted in an increase in the number of foci for Brca1, 53BP1, and Rad51 (Figure 3d and Supplementary Figure S4), but not Atm, Mre11, or Atr (Figure $3 e$ and
Supplementary Figure S5). It is to be noted that the levels of Brca1, 53BP1, and Rad51 were not altered in C-Abl-/MEFs (data not shown). The difference is in agreement with the findings that Mre11 and Rad51 are not co-localized on nuclear foci. ${ }^{24}$ The sustained foci appearance might reflect a delay or a defect in DNA repair, in agreement with an increase in DNA breaks observed in C-Abl-/- cells (Figure $2 e$ and $f)$. Alternatively, c-Abl deficiency may enhance the assembly or inhibit the disassembly of those proteins located at the foci.

We then looked at IR-induced foci formation of $\gamma \mathrm{H} 2 \mathrm{AX}$, a $\mathrm{H} 2 \mathrm{~A}$ variant that is phosphorylated on Ser139 by Atm and other PIKKs at DNA damage sites, which occurs minutes after $\mathrm{IR}$, peaks at $20 \mathrm{~min}$, and disappears within $8 \mathrm{~h}$ after radiation. ${ }^{6}$ We found that the number of $\gamma \mathrm{H} 2 \mathrm{AX}$-positive foci was markedly reduced in c-Abl-/- MEFs (Figure 3f), suggesting that Atm and/or DNA-PKcs activation was compromised in the absence of c-Abl. Moreover, $4 \mathrm{~h}$ after radiation, wild-type MEFs lost the foci to a greater extent than that of $\mathrm{c}-\mathrm{Abl}-/-$ MEFs, suggesting that $c-A b l$ deficiency might delay DNA repair (Figure 3f).

c-Abl deficiency leads to a decrease in the activation of Atm and Atr. Defects in the phosphorylation of p53 and Chk $1 / 2$ and in early $\gamma \mathrm{H} 2 \mathrm{AX}$ foci formation can be attributable to the decreased activity of Atm, Atr, and/or DNA-PKcs. Atm exists as an inactive dimer and its activation is accompanied by autophosphorylation at S1981, which is commonly used as a marker of Atm activation. Western blot analysis of Atm autophosphorylation revealed a reduced activation of Atm in c-Abl-/- MEFs in response to Dox (Figure 4a). Similarly, c-Abl-/- MEFs displayed reduced phosphorylation of Atr on S428 in response to either Dox or HU (Figure $4 b$ and c). Knockdown of c-Abl with siRNA also led to decrease in the phosphorylation of Atm and Atr (Supplementary Figure S6a and $\mathrm{b}$ ). The positive role of $\mathrm{c}$-Abl in Atr activation was confirmed by in vitro kinase assay using p53 as a substrate (Figure 4d). ${ }^{25}$ Moreover, when co-expressed in COS7 cells, c-Abl was able to activate Atr, whereas the kinase-dead c-Abl only showed a marginal effect (Figure 4e). These findings suggest that c-Abl has a positive role in Atm/Atr activation in a kinase-dependent manner.

c-Abl interacts with and phosphorylates Atm and Atr in response to DNA damage. How does c-Abl regulate the activation of Atm and Atr, which are associated with the chromatin or DNA damage-induced foci? We found that c-Abl was also associated with chromatin but not nuclear foci (Supplementary Figure S7 and data not shown). Previous studies have shown that c-Abl interacts with Atm. ${ }^{16}$ Here we found that this interaction was enhanced in response to DNA

Figure 3 c-Abl deficiency differentially alters nuclear foci assembly of TopBP1, Brca1, 53BP1, Rad51, and $\gamma \mathrm{H} 2 \mathrm{AX}$, but not Atm, Mre11, or Atr. (a) C-Abl-/-, c-Abl reconstituted c-Abl-/-, and control MEFs were treated with Dox for different periods of time and then immuno-stained for endogenous TopBP1. (b) Quantitation data from (a) for the number of cells positive for foci. (c) Quantitation data from (a) for the number of foci per cell. (d) Quantitation data from Supplementary Figure S4 showing that c-Abl deficiency led to an increased number of foci for Brca1, 53BP1, and Rad51. Foci-forming cells were counted from three independent experiments. (e) Quantitation data of c-Abl-I- MEFs showing abnormal nuclear foci assembly of Atm, Atr, and Mre11 (also see Supplementary Figure S5). (f) c-Abl-I- and control MEFs were irradiated with 10 Gy and then were stained for $\gamma \mathrm{H} 2 \mathrm{AX}$ at different time points after IR. Right panel: quantitation data 
a
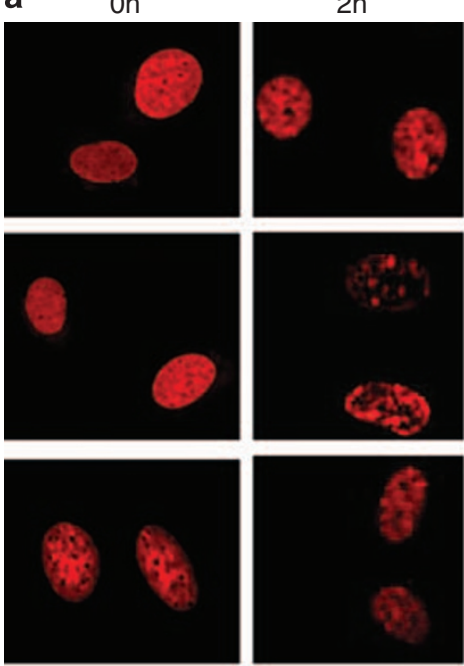

b $90, \pm++$

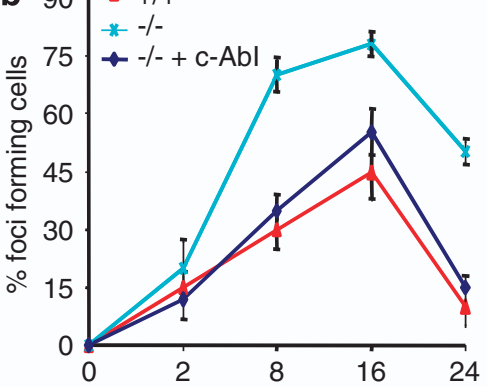

d

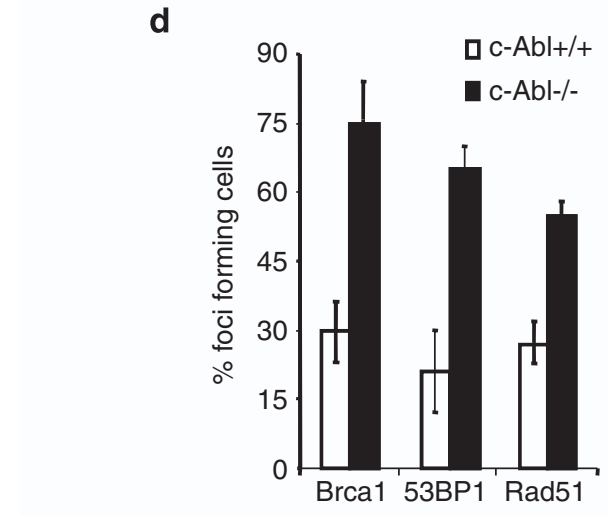

$8 \mathrm{~h}$
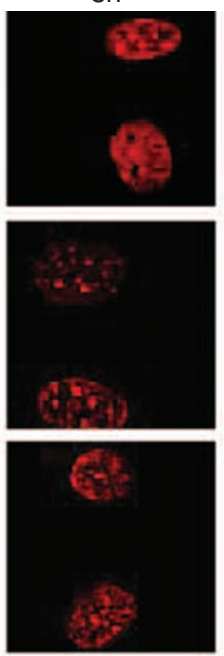

$16 \mathrm{~h}$
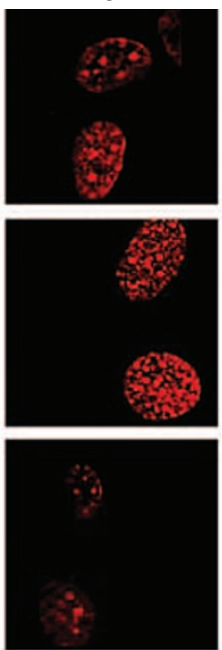

C $21,+++$
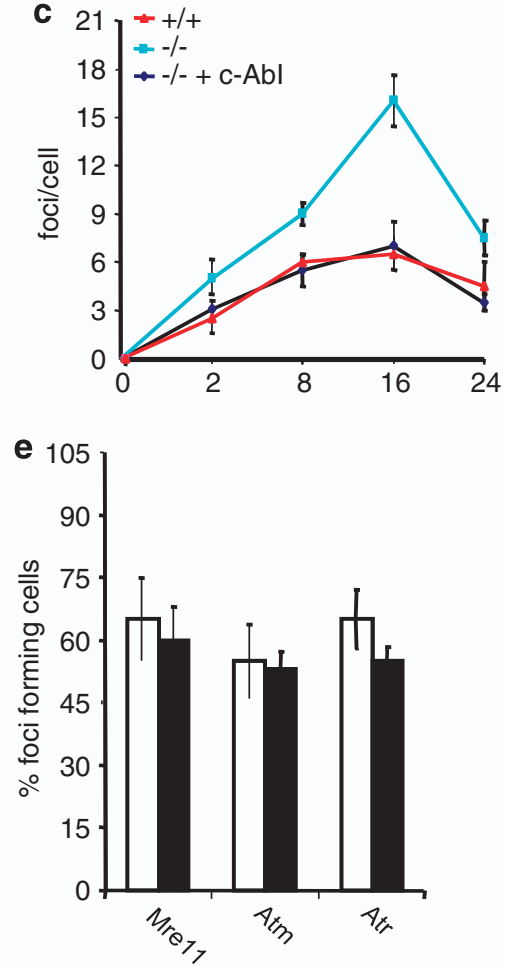

60

c-Abl+/+

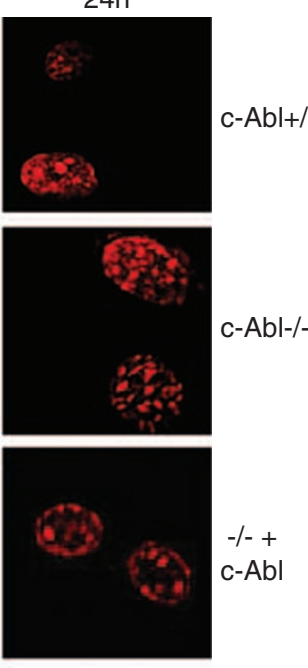

f
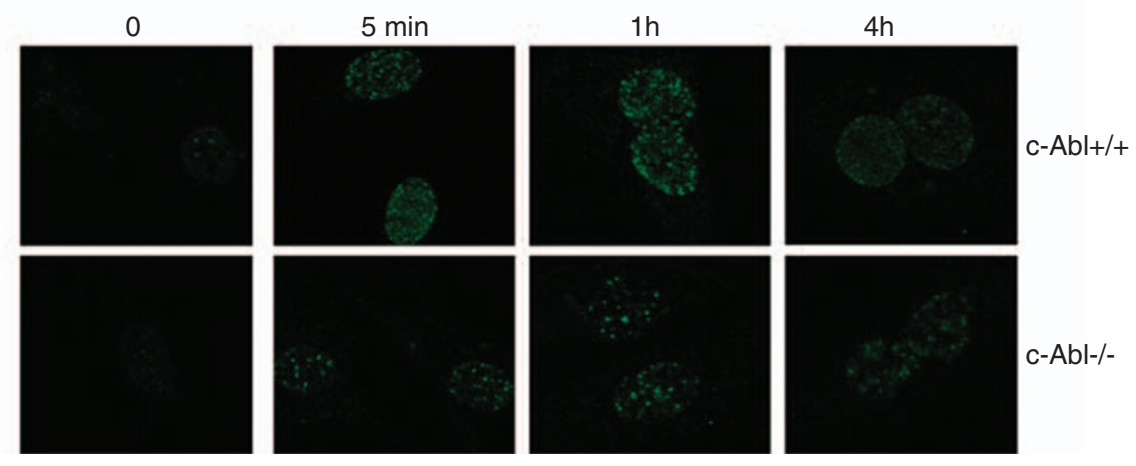
a

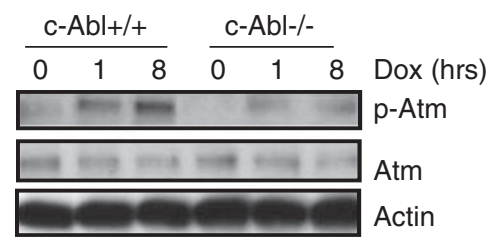

$\begin{array}{llllll}1.5 & 2.9 & 5.8 & 1.0 & 1.5 & 1.8\end{array}$

C b

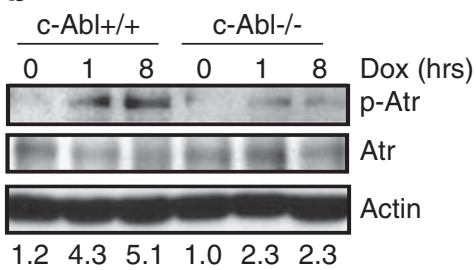

$\begin{array}{llllll}1.2 & 4.3 & 5.1 & 1.0 & 2.3 & 2.3\end{array}$

16 Dox (hrs)

HU (hrs)

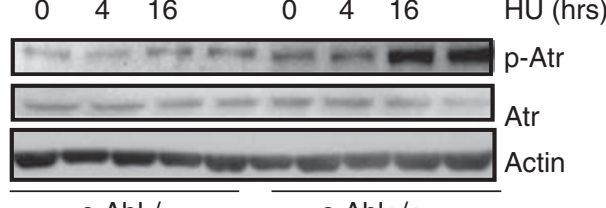

c-Abl-/-

c-Abl+/+

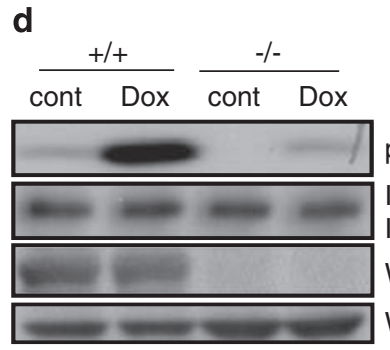

p-GST-p53 S18

IP: ATR

IB: ATR

WB: $c-A b l$

WB: Actin

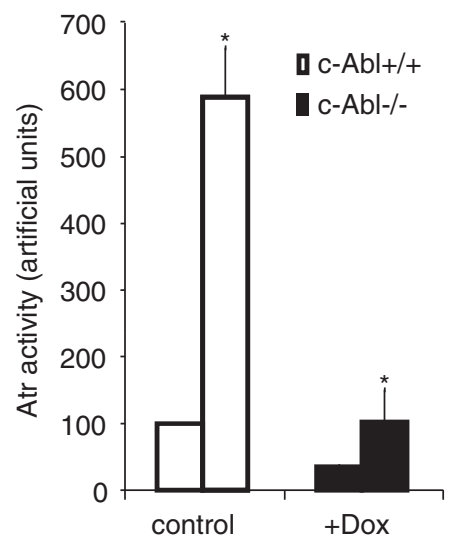

e
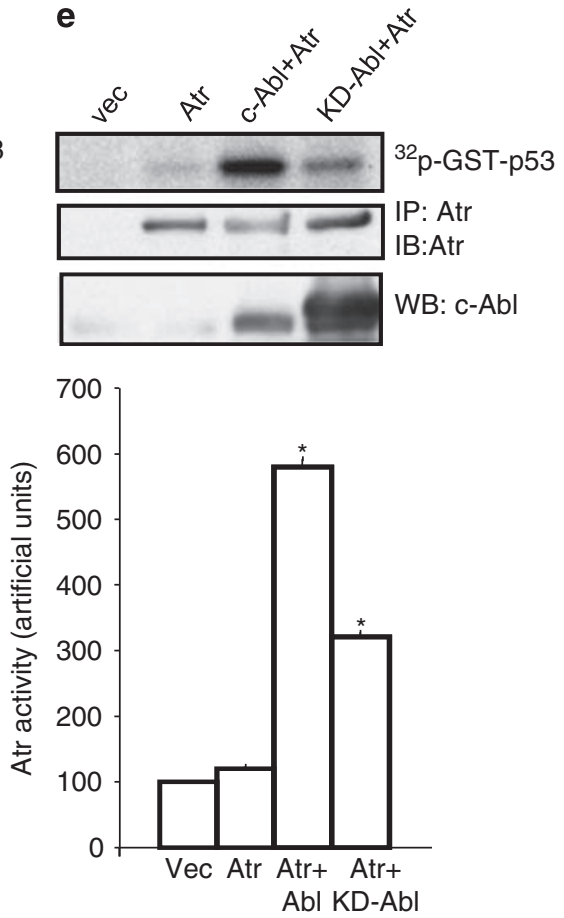

Figure $4 \mathrm{c}-\mathrm{Abl}$ is required for optimal activation of Atm and Atr. (a) Decreased activation of Atm in the absence of c-Abl. c-Abl-I- and control MEFs were treated with Dox for different periods of time and activation of Atm was determined by western blot using an antibody that only recognizes active Atm (S1981-p). For quantitation of Atm activation, the value of phospho-Atm in c-Abl-I-MEFs at basal levels was set at 1.0. (b) Diminished phosphorylation of Atr on S428 in response to Dox in the absence of c-Abl. The experiment was carried out as in (a) and the blot was probed with anti-phospho-Atr antibodies. (c) Diminished phosphorylation of Atr in the absence of c-Abl in response to HU. The experiment was carried out just like (b) except that HU was used. (d) In vitro kinase assay showing that c-Abl deficiency compromised Atr activation. Endogenous Atr was immunoprecipitated from WT or c-Abl-I-MEFs, in the presence or absence of Dox, and was used in a kinase assay with GST-p53 as a substrate. For quantitation of Atr activation, the value of phospho-GST-p53 was normalized to the protein levels of Atr. The value in c-Abl-/- MEFs at basal levels was set at $100 \%$. (e) In vitro kinase assay showing that co-expression of c-Abl led to Atr activation. For activation of Atr, the value of ${ }^{32} \mathrm{P}$-labeled GST-p53 at basal levels was set at $100 \%$

damage, as evidenced in co-immunoprecipitation assays of the endogenous c-Abl and Atm (Figure 5a). Genotoxic stress also enhanced the interaction between $\mathrm{c}$-Abl and Atr (Figure 5b). This interaction was not mediated by DNA, as in the co-IP experiments DNAase pretreatment did not affect the interaction (data not shown). Interaction between endogenous c-Abl and Atm was confirmed in HeLa cells, which was enhanced by Dox treatment (Figure 5c). Moreover, c-Abl and Atr were found to form a complex when co-expressed in COS7 cells, which was also enhanced in the presence of Dox (Figure $5 d$ ).

Physical interaction between c-Abl and Atm/Atr may facilitate activation of Atm/Atr, as TopBP1 does to Atr, ${ }^{11}$ or c-Abl might phosphorylate Atm/Atr and lead to its activation, as CDK5 does to Atm, ${ }^{12}$ or both. Figure $4 \mathrm{e}$ shows that $\mathrm{c}-\mathrm{Abl}$ kinase activity is required for Atr activation. Moreover, ectopically expressed c-Abl was able to phosphorylate Atr (Figure $5 d$, bottom panel). Dox treatment led to tyrosine phosphorylation 
a

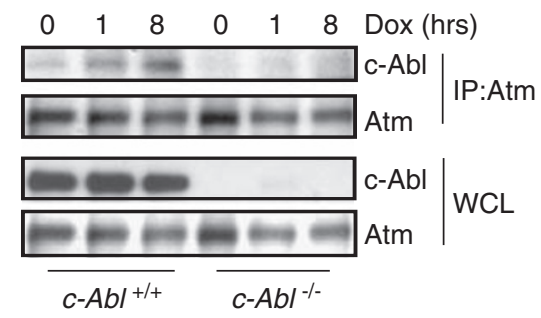

b

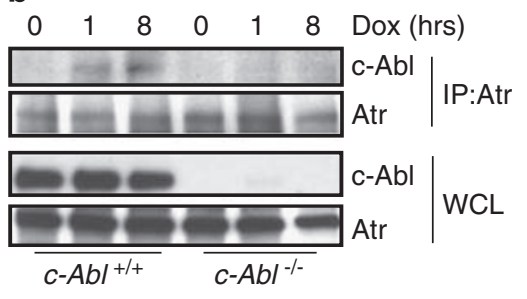

C

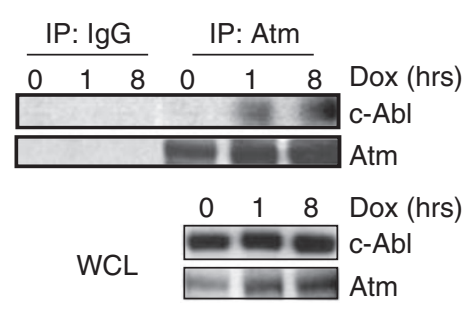

e

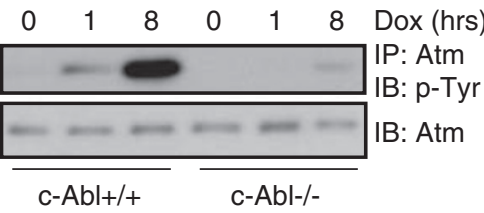

d

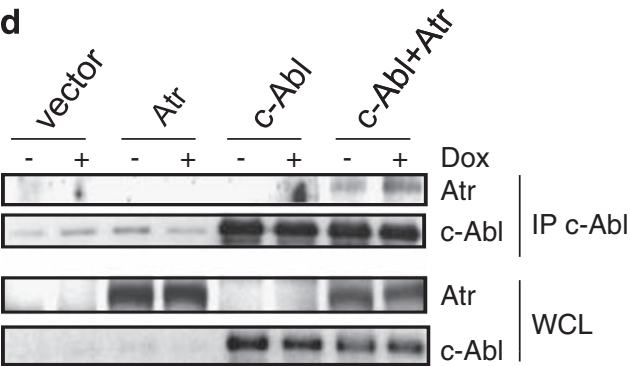

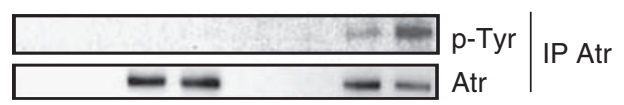

f

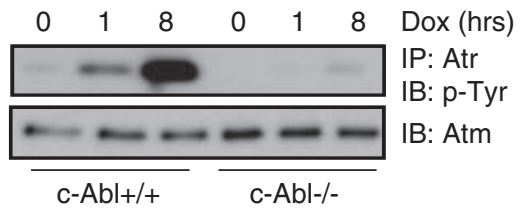

Figure $5 \mathrm{c}$-Abl interacts with Atm and Atr and is required for Atm/Atr phosphorylation in response to genotoxic stress. (a) Enhanced complex formation between c-Abl and Atm. c-Abl-I- and control MEFs were treated with Dox for different periods of time and endogenous Atm was immunoprecipitated. The possibly associated c-Abl was determined by western blot. (b) Enhanced complex formation between c-Abl and Atr in response to DNA damage. The experiment was carried out as in (a) except that anti-Atr antibodies were used for immunoprecipitation. (c) Association of endogenous c-Abl and Atm in HeLa cells. Cell lysates were immunoprecipitated with anti-Atm antibodies or control IgG, followed by immunoblotting with anti-c-Abl antibodies. The whole cell lysate (WCL) was used as a control. (d) Ectopically expressed c-Abl interacted with Atr and could phosphorylate Atr on tyrosine residues. COS7 cells were transfected with indicated expression constructs and the cell lysates were used to do co-IP assays with antic-Abl antibodies. Immunoprecipitated proteins and their associated proteins were detected by western blot analysis using anti-Atr antibodies (upper panel). A second set of cells was used to immunoprecipitate Atr and its tyrosine phosphorylation was detected by using anti-phospho-tyrosine antibodies (PY20) (bottom panel). (e) Atm was tyrosine phosphorylated in a c-Abl-dependent manner. Endogenous Atm was immunoprecipitated from c-Abl- $/$ - and control MEFs that were treated with Dox for different periods of time and its phosphorylation was determined by western blot using PY20. (f) Atr was phosphorylated in response to DNA damage in a c-Abl-dependent manner. The experiment was carried out as in (e) except that anti-Atr antibodies were used for immunoprecipitation

of endogenous Atm and Atr and this phosphorylation was reduced in $\mathrm{c}-\mathrm{Abl}-\mathrm{I}-$ MEFs (Figure $5 \mathrm{e}$ and $\mathrm{f}$ ), indicating a critical role for $\mathrm{c}-\mathrm{Abl}$ in tyrosine phosphorylation of Atm and Atr. To determine whether Dox-induced Atr activation depends on DSBs and Atm activation, we tested Atr S428 phosphorylation in Atm-/- MEFs. It was found that Doxinduced Atr phosphorylation was markedly reduced in Atm-/ - and Atm-/- MEFs with c-Abl knocked down (Supplementary Figure S8), suggesting that Atr activation might relies on Atm activation under this condition.

Identification of Y291 and Y310 as c-Abl phosphorylation sites important for Atr activation. The above results suggest that tyrosine phosphorylation of Atm/ Atr by c-Abl might have a role in their activation. Atm and Atr are large proteins $(>250 \mathrm{kDa}$ ) with multiple domains. In this study, we chose Atr to study the mechanisms by which c-Abl regulates its activation because the Atm expression construct readily undergoes recombination in the process of bacterial amplification. We generated five Atr fragments (F1-F5) to cover the full protein sequence of Atr (Figure 6a), each of which was co-expressed with c-Abl in COS7 cells, immunoprecipitated, and its tyrosine phosphorylation was assessed by western blot (Figure $6 \mathrm{a}$ and Supplementary Figure S9a). It appears that the 'N' terminal F1 (aa 1-528) was the major fragment phosphorylated by c-Abl. Further experiments show that fragment F1b, but not F1c, could be phosphorylated by c-Abl (Figure 6a and Supplementary Figure S9b). Sequence comparison revealed that several $Y$ residues in the divergent region between $\mathrm{F} 1 \mathrm{~b}$ and $\mathrm{F} 1 \mathrm{c}$ are conserved among mouse, rat and humans. Mutagenesis analysis of each of these $Y$ residues ( $Y$ to $F$ ) revealed that Y291 and Y310 are the major phosphorylation sites (based on human Atr protein sequence) (data not shown), which are 


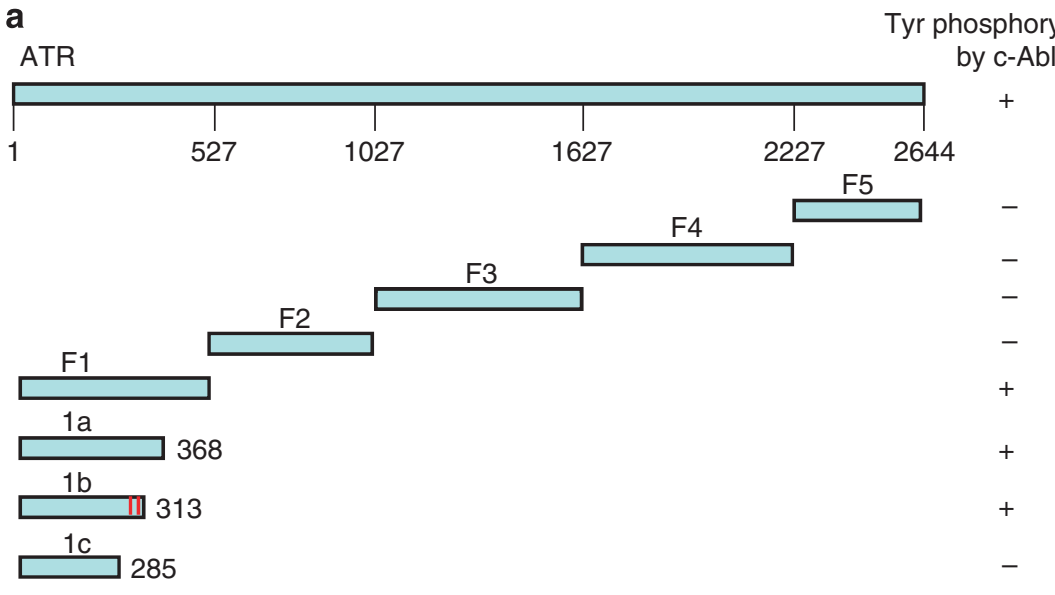

II Y291,Y310

b

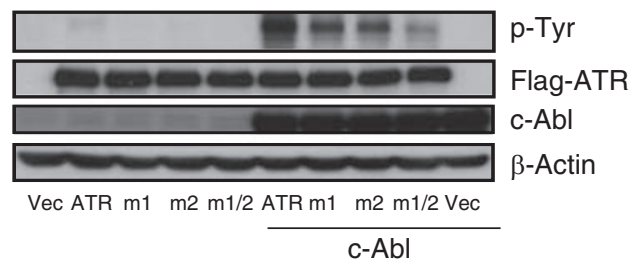

C

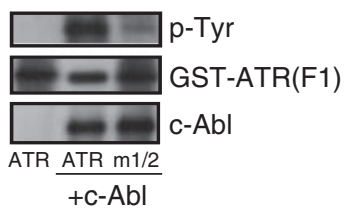

Figure 6 c-Abl phosphorylates Atr on Y291/310. (a) A diagram showing various fragments of ATR and their Y phosphorylation status when co-expressed with c-Abl. (b) Y291/310 are the major phosphorylation sites on Atr by c-Abl. Full-length WT ATR or ATR carrying Y291F, Y310F, or Y291/310F mutation was co-expressed with c-Abl in COS7 cells, immunoprecipitated with anti-Flag antibody (for ATR), and assessed for tyrosine phosphorylation by western blot analysis. (c) c-Abl was able to phosphorylate ATR on Y291/310 in in vitro kinase assays. GST-ATR(F1) and GST-ATR(m1/2) were expressed and purified from bacteria, and were used in in vitro c-Abl kinase assay. Phosphorylation was determined by western blot analysis

located in a HEAT repeat and between two HEAT repeats, respectively. ${ }^{26}$ We then introduced Y291F (m1), Y310F (m2), or Y291/310F (m1/2) mutation into the full-length ATR, which was confirmed with sequencing. When they were coexpressed with c-Abl, we found that both Y291 and Y310 were phosphorylated by c-Abl (Figure 6b). Using purified GST-ATR (F1) as a substrate in an in vitro c-Abl kinase assay, we showed that Atr was a direct substrate of $\mathrm{c}$-Abl and that Y291 and $\mathrm{Y} 310$ are the major sites for $\mathrm{c}-\mathrm{Abl}$ phosphorylation (Figure 6c).

We then reconstituted Atr-deficient Seckel syndrome fibroblasts with WT, $\mathrm{m} 1$, or $\mathrm{m} 2$ mutant ATR, to test the possible effects of the phosphorylation on ATR activation in response to $\mathrm{HU}$. It was found that ATR $\mathrm{m} 1$ or $\mathrm{m} 2$ mutant, unlike wild-type ATR, could not be fully activated by $\mathrm{HU}$ treatment (Figure 7a). We then tested p53 phosphorylation in response to $\mathrm{HU}$. It was found that ATR-deficient cells could still respond to $\mathrm{HU}$, although the basal level of p53 S18 phosphorylation was very low, probably due to the hypomorphic nature of ATR in these cells (Figure 7b). WT ATR expression increased p53 S18 phosphorylation at the basal level and in response to $\mathrm{HU}$. However, cells with $\mathrm{m} 1$ or $\mathrm{m} 2$ mutant ATR, even expressed at similar levels to wild-type ATR, showed an increased basal level of p53 S18 phosphorylation, but did not further respond to genotoxic stress (Figure 7b), suggesting that the ATR mutants might have basal activities but could not be fully activated in response to genotoxic stress. Similarly, in these cells, HU-induced Chk1 phosphorylation was enhanced by wild-type ATR, but not by the $\mathrm{m} 1$ or $\mathrm{m} 2 \mathrm{ATR}$ (Figure $7 \mathrm{c}$ ). In addition, the decreased $\mathrm{HU}$-induced nuclear foci formation for $\gamma \mathrm{H} 2 \mathrm{AX}$ in ATR-deficient cells was rescued by wild-type ATR, but not by the mutant $\mathrm{m} 1$ or m2 ATR (Figure 7d). These results collectively indicate that Y291 and Y310 are critical for ATR activation.

\section{Discussion}

The current study provides evidence that non-receptor tyrosine kinase c-Abl regulates Atm and Atr, two kinases at the center of DNA damage-triggered signaling cascades, in addition to p53 and p73. c-Abl might execute its function at chromatin, where it interacts with Atm/Atr and phosphorylates Atm/Atr on tyrosine residues. c-Abl deficiency results in defects in Atm/Atr activation and Atm/Atr-controlled events including phosphorylation of Chk1, Chk2 and p53, nuclear foci formation of $\gamma \mathrm{H} 2 \mathrm{AX}$, cell cycle progression, and apoptosis. Interestingly, c-Abl-deficient mice show more similarities to Atm-deficient mice than to p53-deficient mice. For example, both c-Abl and Atm knockout mice show growth retardation, infertility, immune deficiency, and osteoporosis. ${ }^{27-29}$ In addition, whereas Atr knockout mice show early embryonic lethality, hypomorphic mutations in the Atr gene have been linked to Seckel syndrome in human, a disorder with features like growth retardation, microcephaly, and abnormal facial and skeletal development. ${ }^{30,31}$ Thus $\mathrm{c}$-Abl could be an important regulator of Atm/Atr. Recent studies have shown that TopBP1 can activate Atr by forming a TopBP1-Atr-ATRIP complex, ${ }^{11,13}$ and CDK5, a cyclin-dependent kinase that is 
a

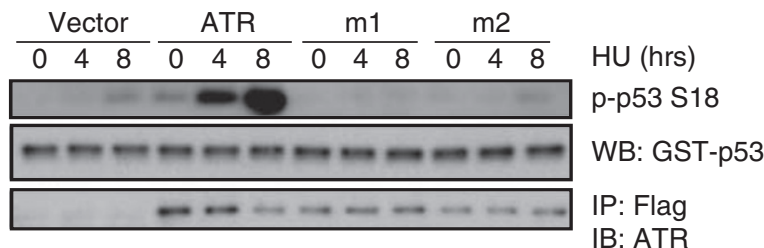

b
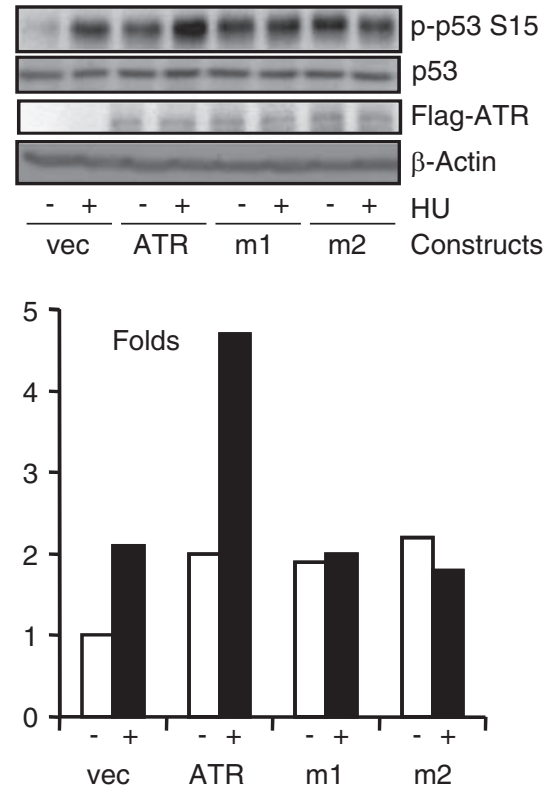
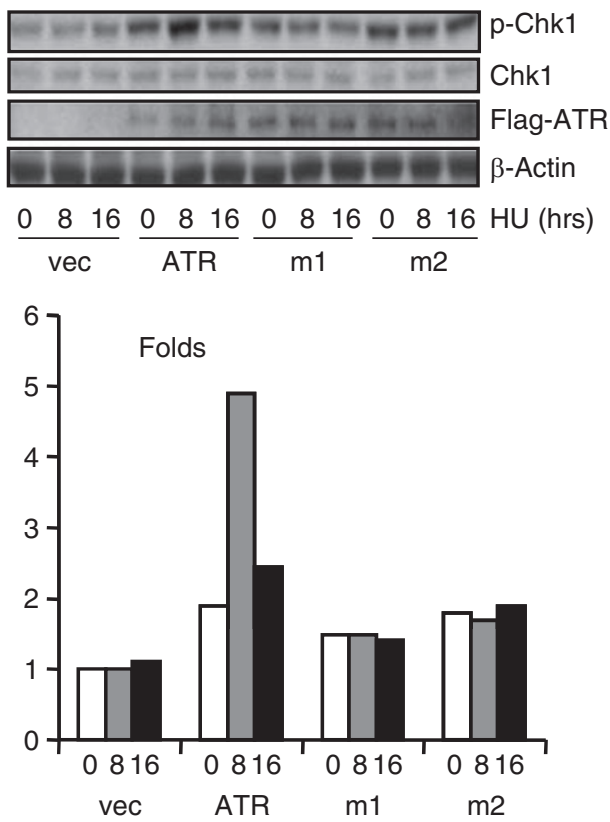

d 0 4 hrs
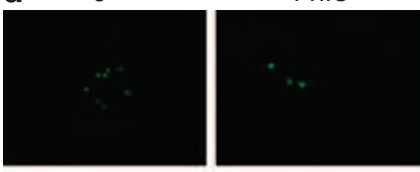

$8 \mathrm{hrs}$
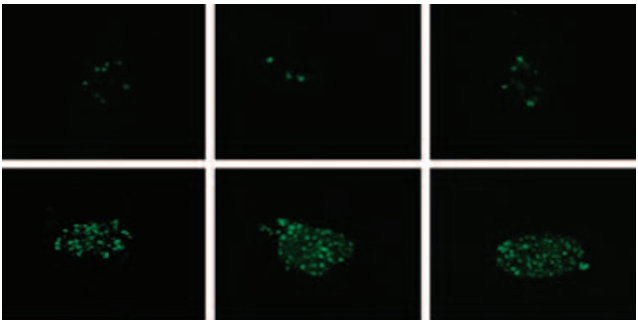

vector
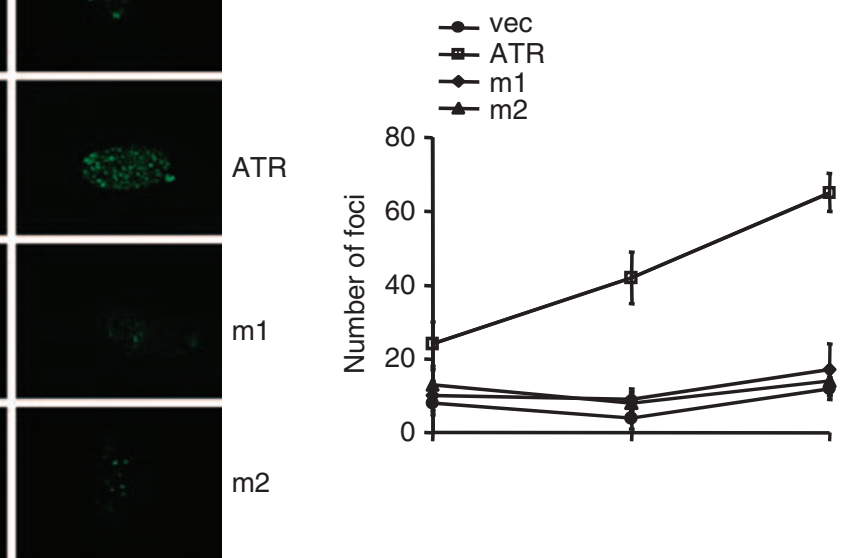

Figure 7 Evidence that $\mathrm{Y} 291$ and $\mathrm{Y} 310$ are required for ATR activation. (a) In vitro kinase assay showing that Y291F and Y310F mutations diminished ATR activity. ATR-deficient cells were transfected with vectors expressing wild-type, $\mathrm{m} 1$, or m2 mutant ATR for 2 days, which were then treated with HU for 4 or $8 \mathrm{~h}$. ATR was immunoprecipitated with anti-Flag antibodies and was used in a kinase assay with GST-p53 as a substrate. (b) Y291 and Y310 are important for ATR-mediated p53 phosphorylation on $\mathrm{S} 18$ in vivo. WT ATR or ATR carrying Y291F (m1) or Y310F (m2) mutation was expressed in ATR-deficient fibroblasts (with Neo-pcDNA vector) for $24 \mathrm{~h}$ and then selected for $48 \mathrm{~h}$ or more. The cells were then challenged with $\mathrm{HU}$ for $8 \mathrm{~h}$ and then collected. ATR, p53, p-p53, p21, and actin were analyzed by western blot. Bottom panel: quantitation data. (c) Y291 and Y310 are important for ATR-mediated Chk1 phosphorylation in vivo. The experiments were carried out as in (b) and Chk1 phosphorylation and Chk1 protein levels were determined by western blot. Bottom panel: quantitation data. The value of p-p53 in ATR-deficient cells with control vector at time 0 was set at 1. (d) $Y 291$ and $Y 310$ are important for ATR-mediated $\gamma H 2 A X$ nuclear foci formation. ATR-deficient cells were transfected with vectors expressing wild-type, m1, or m2 mutant ATR for 2 days, which were then treated with $\mathrm{HU}$ for 4 or $8 \mathrm{~h}$. $\gamma \mathrm{H} 2 \mathrm{AX}$ was detected with immunostaining by anti- $\gamma \mathrm{H} 2 \mathrm{AX}$ antibodies. Right panel: quantitation data. The value of $p$-p53 in ATR-deficient cells with control vector at time 0 was set at 1 
involved in neuron maturation and migration but not in cell cycle control, can activate Atm by phosphorylating Atm on S794. ${ }^{12}$ Interestingly, both TopBP1 and CDK5 are established interacting partners of $\mathrm{C}-\mathrm{Abl}{ }^{21}$ This raises a possibility that complexes of c-Abl, CDK5, and TopBP1 might regulate Atm/Atr activation at the DNA breaks.

This study revealed a novel role for c-Abl in DNA damage response pathways that involves Atr in addition to its role in response to DSBs. ${ }^{32} \mathrm{c}-\mathrm{Abl}$ can be activated by $\mathrm{HU}$ and is required for genotoxic stress-induced tyrosine phosphorylation of Atr, full activation of Atr, Chk1 activation, and $\mathrm{HU}$-induced cell death. Even in cell response to IR and Dox, c-Abl seems to have a role at steps that involve ssDNA, which can be generated by resection of the DSBs. Firstly, the increase in the number of foci in $\mathrm{c}-\mathrm{Abl}-/-$ cells is more evident at later time, indicating a defect in the slow repair process (HRR). Secondly, these foci were positive for Brca1 and Rad51, proteins involved in HRR. ${ }^{33}$ Thirdly, c-Abl-/MEFs accumulate an increased number of ssDNA. However, whether the repair defects observed in c-Abl-/- MEFs were mediated by the compromised activation of Atm/Atr needed further investigation. ${ }^{14,34}$

Based on these findings, we propose the following model to explain a possible role for $\mathrm{c}$-Abl in cell response to DSBs. Once DSBs occur, Atm is localized onto DSBs and is activated in a MRN complex-dependent but c-Abl independent manner. Atm further phosphorylates and activates its interacting protein $\mathrm{c}-\mathrm{Abl}$, which in turn phosphorylates Atm and helps to further activate Atm. At the same time, ssDNA is generated by resection of the DSBs, followed by assembly of Atr and associated proteins at those sites. Activated c-Abl interacts with and phosphorylates Atr, facilitating the maximal activation of Atr. Therefore, $\mathrm{c}$-Abl may function to relay signals from DSB response to ssDNA response under this condition. An implication of this study is that clinical use of Abl kinase inhibitor STI571 in chronic myelogenous leukemia treatment might compromise cell response to DNA damage in the patients, leading to accumulation of more secondary mutations. $^{35-37}$

In addition to positively regulating Atm/Atr activation, our study shows that $\mathrm{c}$-Abl might have an important role in regulating foci formation of proteins like 53BP1, TopBP1, Rad51, and Brca1. This might not be attributable to compromised Atm/Atr activation as Atm/Atr deficiency or inhibition usually leads to a decrease in foci formation of these proteins. Instead, this can be mediated by interaction between C-Abl and these proteins. ${ }^{20,21}$ On the other hand, whereas compromised Atm/Atr activation is likely the main reason for the defects in p53 and Chk1/Chk2 phosphorylation in c-Abl-/- MEFs, the abnormal foci formation of the adaptor proteins might also contribute, as a dynamic assembly/ disassembly of the adaptor proteins have an important role in this event.

In summary, this study provides evidence that c-Abl might have roles at multiple steps in cell response to DSBs. A major role for c-Abl is to interact with Atm/Atr and help to activate these two kinases, their downstream signaling events, and related cellular events; $c$-Abl also regulates foci formation and DNA repair, which may not be mediated by altered Atm/Atr activation and requires further investigation.

\section{Materials and Methods}

Cell culture and transfection. Mouse embryonic fibroblasts (p3-p5) were prepared as previously described. ${ }^{38}$ MEFs were cultured in DMEM supplemented with $10 \% \mathrm{FCS}$ and penicillin/streptomycin in an atmosphere of $5 \% \mathrm{CO}_{2}$ at $37^{\circ} \mathrm{C}$. Human ATR null cells were purchased from Coriell Cell Repositories (GM101887 and GM18366 pair). In all experiments, MEFs were isolated from at least three $\mathrm{c}-\mathrm{Abl}-1-$ mice and their control littermates (in $\mathrm{C} 57 \mathrm{BL} / 6$ background). For cell transfection into COS7 cells, lipofectamine was used following the manufacturer's protocol. To generate DNA damage, cells were treated with Dox (CalBiochem, Brookfield, WI, USA), aphidicolin, and hydroxyurea (Sigma, St Louis, MO, USA). STI571 was a gift from Novartis, Singapore.

Cell fractionation, western blot analysis, and kinase assay. For western blot, cells were lysed with RIPA buffer supplemented with proteinase inhibitors. Protein concentration was determined by Bio-Rad (Hercules, CA, USA) assay. For immunoprecipitation experiments, cell lysates were incubated with primary antibodies against Atm, Atr, or Flag (Atr tag) overnight at $4^{\circ} \mathrm{C}$, and then incubated with protein $A$ plus $G$ beads. For immunoblotting, proteins were resolved by SDS-PAGE and were transferred to polyvinylidene difluoride membranes (PVDF, Millipore, Piscataway, NJ, USA), followed by incubation with primary and secondary antibodies and detected by ECL kit (Amersham Biosciences, Billerica, MA, USA). Antibodies against Atr were purchased from Abcam, Cambridge, MA, USA. Antibodies against Flag and actin were from Sigma. Antibodies against phosphoChk1 (S345), phospho-Chk2 (T68), phospho-p53 (S18), phospho-Atr (S428), Chk1, Chk2, and p53 were from Cell Signaling (Danvers, MA, USA). Antibodies against phospho-Atm (S1981) were from Rockland (Gilbertsville, PA, USA) and anti-Atm and anti-c-Abl antibodies were from CalBiochem. PY20 and anti-p21 antibodies were from Biochem Diagnostic (San Jose, CA, USA). Kinase assay for c-Abl was carried out as previously described, using GST-Crk as a substrate, ${ }^{38}$ which was detected either with ${ }^{32} \mathrm{P}$-labeling on a SDS-PAGE gel or by anti-p-Tyr antibody on a western blot. Atr kinase assay was carried out as previously described, using GSTp53 as a substrate, ${ }^{25}$ except that reaction time was shortened to $15 \mathrm{~min}$ at room temperature.

Immunofluorescence staining. Cells were grown overnight on glass cover-slips, subjected to Dox treatment, and were fixed with $4 \%$ paraformaldehyde and permeabilized with $0.1 \%$ Triton X-100 for $20 \mathrm{~min}$, and then incubated with primary and Texas Red- or FITC-conjugated secondary antibodies. Mouse antibody to TopBP1 was from Biomed Diagnostics (San Diego, CA, USA). Mouse antibody to Brca1, rabbit antibody to 53BP1 and Atr were from Calbiochem. Goat antibody to Rad51 and rabbit antibody to Atr were from Santa Cruz (Santa Cruz, CA, USA). Rabbit antibody to $\gamma \mathrm{H} 2 \mathrm{AX}$ was from BETHYL Lab, Inc. (Montgomery, TX, USA) Rabbit antibody to Mre11 was from Novus Biological (Littleton, CO, USA).

TUNEL assay and cell cycle analysis. Apoptosis was detected with Roche (Basel, Switzerland) TUNEL assay kit following the manufacturer's protocol after the cells were treated with $\mathrm{HU}$ or Dox for $24 \mathrm{~h}$. Cell cycle analysis was carried out as previously described. ${ }^{27}$

Cell cycle checkpoint assays. Radio-resistant DNA synthesis (RDS assay) was performed as previously described. ${ }^{6}$ Briefly, cells were incubated in the presence of $10 \mathrm{nCi} / \mathrm{ml}^{14} \mathrm{C}$ thymidine (NEN) overnight and then incubated with normal medium for $24 \mathrm{~h}$ or more. The cells were then irradiated, labeled at 1,5 , or $21 \mathrm{~h}$ after radiation with $2.5 \mu \mathrm{Ci} / \mathrm{ml}^{3} \mathrm{H}$ thymidine (NEN) for $3 \mathrm{~h}$, and then collected. Cells were washed twice with phosphate-buffered saline (PBS), fixed in $70 \%$ methanol, and then transferred to Whatman filters and fixed sequentially with 70 and $95 \%$ methanol. The filters were air-dried and the radioactivity was measured in a liquid scintillation counter. The resulting ratio of ${ }^{3} \mathrm{H}$ (c.p.m.) to ${ }^{14} \mathrm{C}$ (c.p.m.) was used as an indication of RDS. The ratio at time 0 was set at $100 \%$.

For G2/M checkpoint assay, cells were exposed to IR or Dox and harvested at different time points after irradiation, washed with PBS, and fixed in suspension with $70 \%$ ethanol. The cells were then incubated in PBS containing $0.25 \%$ Triton X-100 for $15 \mathrm{~min}$. The cells were blocked with PBS containing $1 \%$ bovine serum albumin for $30 \mathrm{~min}$, incubated with polyclonal antibodies that specifically recognize the phosphorylated form of histone $\mathrm{H} 3$ (Upstate Waltham, MA, USA) for $3 \mathrm{~h}$, and then FITC-conjugated secondary antibody (Jackson ImmunoResearch Laboratories Inc., West Grove, PA, USA). The cells were washed again, resuspended in $25 \mu \mathrm{g}$ of propidium iodide (PI) and $0.1 \mathrm{mg}$ of RNase A (Sigma) $/ \mathrm{ml}$ in PBS, and incubated at room temperature for $30 \mathrm{~min}$. Cellular fluorescence was measured by a flow 
cytometer or cell sorter. The number of phospho-H3-positive cells at time 0 was set at $100 \%$.

Single-cell gel electrophoresis (Comet) assay. MEFs were plated at $4.5 \times 10^{5}$ cells per $35 \mathrm{~mm}$ tissue culture dish and irradiated at 2.5 Gy for $30 \mathrm{~min}$ and $24 \mathrm{~h}$. The treated cells and untreated cells were harvested by trypsinization, washed in ice-cold PBS buffer and suspended in HBSS with $10 \%$ DMSO with EDTA. The cells were then resuspended in $0.75 \%$ molten low-melting-point agarose at $42^{\circ} \mathrm{C}$ and immediately pipetted onto the comet slides (Trevigen, Gaithersburg, MD, USA). Cells were lysed in prechilled lysis solution at $4{ }^{\circ} \mathrm{C}$ for $1 \mathrm{~h}$. Alkaline unwinding was done at $\mathrm{pH}>13$ for $40 \mathrm{~min}$. Alkaline electrophoresis (25 V, 300 mA for $20 \mathrm{~min}$ ) in alkaline solution $(\mathrm{pH}>13)$ was performed to detect the double- and single-stranded breaks. Neutral electrophoresis ( $25 \mathrm{~V}$ for $10 \mathrm{~min}$ ) was performed using TBE buffer to detect double-stranded breaks. After electrophoresis, slides were briefly rinsed in neutralization buffer ( $500 \mathrm{mM}$ Tris- $\mathrm{HCl}, \mathrm{pH} 7.5)$, dehydrated in $70 \%$ ethanol, airdried, and stained with SYBR green dye. The tail moment of the comets was generated using the Metasystems (Heidelberg, Germany) analysis software 'Comet imager version 1.2'. Fifty randomly chosen comets were analyzed per sample. The extent of DNA damage observed was expressed as tail moment, which corresponded to the fraction of DNA in the tail of the comet.

Image acquisition, quantitation of western blot, and statistical analysis. All the presented data have been repeated at least three times, with similar results being obtained. The results from one experiment were presented. For quantitation, western blot results were scanned with a Molecular Dynamics scanning densitometer. Statistical analysis was performed using Student's $t$-test. Significant association was defined when $P<0.05$ as compared with control.

\section{Conflict of interest}

The authors declare no conflict of interest.

Acknowledgements. We thank Drs. Alan Porter, Victor Yu, Uttam Surana, Wai Fook Leong, and Huiyi Kua for helpful discussions, Hang In lan, Choon Hong Goh, and Yew Man Lee for technical support, and Drs. Michael Kastan, Karlene Cimprich, Jean Wang, Ann Marie Pendergast, and Novartis for providing expression constructs, cell lines, and reagents. This work was supported by the Agency for Science, Technology and Research of the Republic of Singapore. MPH acknowledges support from the National University of Singapore and National Medical Research Council, Singapore.

1. Peterson CL, Cote J. Cellular machineries for chromosomal DNA repair. Genes Dev 2004 18: $602-616$.

2. Abraham RT. Cell cycle checkpoint signaling through the ATM and ATR kinases. Genes Dev 2001; 15: 2177-2196.

3. Shiloh Y. ATM and related protein kinases: safeguarding genome integrity. Nat Rev Cancer 2003; 3: 155-168.

4. Cline SD, Hanawalt PC. Who's on first in the cellular response to DNA damage? Nat Rev Mol Cell Biol 2003; 4: 361-372.

5. D'Amours D, Jackson SP. The Mre11 complex: at the crossroads of dna repair and checkpoint signalling. Nat Rev Mol Cell Biol 2002; 3: 317-327.

6. Kitagawa R, Bakkenist CJ, McKinnon PJ, Kastan MB. Phosphorylation of SMC1 is a critical downstream event in the ATM-NBS1-BRCA1 pathway. Genes Dev 2004; 18: 1423-1438.

7. Lisby M, Rothstein R. DNA damage checkpoint and repair centers. Curr Opin Cell Biol 2004; 16: 328-334

8. Jazayeri A, Balestrini A, Garner E, Haber JE, Costanzo V. Mre11-Rad50-Nbs1-dependent processing of DNA breaks generates oligonucleotides that stimulate ATM activity. EMBO J 2008; 27: 1953-1962.

9. Shiotani B, Zou L. Single-stranded DNA orchestrates an ATM-to-ATR switch at DNA breaks. Mol Cell 2009; 33: 547-558.

10. Burdak-Rothkamm S, Rothkamm K, Prise KM. ATM acts downstream of ATR in the DNA damage response signaling of bystander cells. Cancer Res 2008; 68: 7059-7065.
11. Mordes DA, Glick GG, Zhao R, Cortez D. TopBP1 activates ATR through ATRIP and a PIKK regulatory domain. Genes Dev 2008; 22: 1478-1489.

12. Tian $B$, Yang $Q$, Mao Z. Phosphorylation of ATM by Cdk5 mediates DNA damage signalling and regulates neuronal death. Nat Cell Biol 2009; 11: 211-218.

13. Burrows AE, Elledge SJ. How ATR turns on: TopBP1 goes on ATRIP with ATR. Genes Dev 2008; 22: 1416-1421.

14. Cimprich KA, Cortez D. ATR: an essential regulator of genome integrity. Nat Rev Mol Cell Biol 2008; 9: 616-627.

15. Shaul Y. c-Abl: activation and nuclear targets. Cell Death Differ 2000; 7: 10-16.

16. Baskaran R, Wood LD, Whitaker LL, Canman CE, Morgan SE, Xu Y et al. Ataxia telangiectasia mutant protein activates $\mathrm{c}-\mathrm{Abl}$ tyrosine kinase in response to ionizing radiation. Nature 1997; 387 : 516-519.

17. Shafman T, Khanna KK, Kedar P, Spring K, Kozlov S, Yen T et al. Interaction between ATM protein and c-Abl in response to DNA damage. Nature 1997; 387: 520-523.

18. Yuan ZM, Shioya $H$, Ishiko $T$, Sun $X$, Gu J, Huang YY et al. p73 is regulated by tyrosine kinase C-Abl in the apoptotic response to DNA damage. Nature 1999; 399: 814-817.

19. Liu ZG, Baskaran R, Lea-Chou ET, Wood LD, Chen Y, Karin M et al. Three distinct signalling responses by murine fibroblasts to genotoxic stress. Nature 1996; $\mathbf{3 8 4}$ : 273-276.

20. Yuan ZM, Huang Y, Ishiko T, Nakada S, Utsugisawa T, Kharbanda S et al. Regulation of Rad51 function by c-Abl in response to DNA damage. J Biol Chem 1998; 273: 3799-3802.

21. Zeng L, Hu Y, Li B. Identification of TopBP1 as a c-Abl-interacting protein and a repressor for c-Abl expression. J Biol Chem 2005; 280: 29374-29380.

22. Bartek J, Bartkova J, Lukas J. DNA damage signalling guards against activated oncogenes and tumour progression. Oncogene 2007; 26: 7773-7779.

23. Collins I, Weber A, Levens D. Transcriptional consequences of topoisomerase inhibition. Mol Cell Biol 2001; 21: 8437-8451.

24. Maser RS, Monsen KJ, Nelms BE, Petrini JH. hMre11 and hRad50 nuclear foci are induced during the normal cellular response to DNA double-strand breaks. Mol Cell Biol 1997; 17: 6087-6096.

25. Kim ST, Lim DS, Canman CE, Kastan MB. Substrate specificities and identification of putative substrates of ATM kinase family members. J Biol Chem 1999; 274: 37538-37543.

26. Perry J, Kleckner N. The ATRs, ATMs, and TORs are giant HEAT repeat proteins. Cell 2003; 112: 151-155.

27. Li B, Boast S, de los SK, Schieren I, Quiroz M, Teitelbaum SL et al. Mice deficient in $\mathrm{Abl}$ are osteoporotic and have defects in osteoblast maturation. Nat Genet 2000; 24: 304-308

28. Xu Y, Ashley T, Brainerd EE, Bronson RT, Meyn MS, Baltimore D. Targeted disruption of ATM leads to growth retardation, chromosomal fragmentation during meiosis, immune defects, and thymic lymphoma. Genes Dev 1996; 10: 2411-2422.

29. Rasheed N, Wang X, Niu QT, Yeh J, Li B. Atm-deficient mice: an osteoporosis model with defective osteoblast differentiation and increased osteoclastogenesis. Hum Mol Genet 2006; 15: 1938-1948.

30. Alderton GK, Joenje H, Varon R, Borglum AD, Jeggo PA, O'Driscoll M. Seckel syndrome exhibits cellular features demonstrating defects in the ATR-signalling pathway. Hum $\mathrm{Mol}$ Genet 2004: 13: 3127-3138.

31. Preyer M, Shu CW, Wang JY. Delayed activation of Bax by DNA damage in embryonic stem cells with knock-in mutations of the Abl nuclear localization signals. Cell Death Differ 2007: 14: 1139-1148.

32. Agami R, Blandino G, Oren M, Shaul Y. Interaction of c-Abl and p73alpha and their collaboration to induce apoptosis. Nature 1999; 399: 809-813.

33. Raderschall E, Golub El, Haaf T. Nuclear foci of mammalian recombination proteins are located at single-stranded DNA regions formed after DNA damage. Proc Natl Acad Sci USA 1999; 96: 1921-1926.

34. Chen G, Yuan SS, Liu W, Xu Y, Trujillo K, Song B et al. Radiation-induced assembly of Rad51 and Rad52 recombination complex requires ATM and c-Abl. J Biol Chem 1999; 274 : 12748-12752.

35. Fanta S, Sonnenberg M, Skorta I, Duyster J, Miething C, Aulitzky WE et al. Pharmacological inhibition of c-Abl compromises genetic stability and DNA repair in BcrAbl-negative cells. Oncogene 2008; 27: 4380-4384.

36. Druker BJ. Circumventing resistance to kinase-inhibitor therapy. N Engl J Med 2006; 354: 2594-2596.

37. Wong S, Witte ON. The BCR-ABL story: bench to bedside and back. Annu Rev Immunol 2004; 22: 247-306

38. Li B, Wang X, Rasheed N, Hu Y, Boast S, Ishii T et al. Distinct roles of C-Abl and Atm in oxidative stress response are mediated by protein kinase C delta. Genes Dev 2004; 18: 1824-1837.

\section{Supplementary Information accompanies the paper on Cell Death and Differentiation website (http://www.nature.com/cdd)}

